\title{
Developing a Kano-Based Evaluation Model for Innovation Design
}

\author{
Chang-Tzuoh Wu, ${ }^{1}$ Ming-Tang Wang, ${ }^{1}$ Nien-Te Liu, ${ }^{2}$ and Tien-Szu Pan ${ }^{3}$ \\ ${ }^{1}$ Department of Industrial Design, National Kaohsiung Normal University, Kaohsiung 824, Taiwan \\ ${ }^{2}$ Department of Product Design, Shu-Te University, Kaohsiung 824, Taiwan \\ ${ }^{3}$ Department of Electronic Engineering, National Kaohsiung University of Applied Science, Kaohsiung 807, Taiwan
}

Correspondence should be addressed to Chang-Tzuoh Wu; ctwu4142@gmail.com

Received 9 August 2014; Accepted 5 October 2014

Academic Editor: Stephen D. Prior

Copyright (C) 2015 Chang-Tzuoh Wu et al. This is an open access article distributed under the Creative Commons Attribution License, which permits unrestricted use, distribution, and reproduction in any medium, provided the original work is properly cited.

\begin{abstract}
This research focuses on developing a psychology-based evaluation procedure for innovative design. The divergent thinking part of the main innovative design procedure which discussed in this paper is the extensive QFD developed by the author (Wu). The major performance of QFD is to identify the customers' requirements and their priorities. Then, the proposed extensive QFD helps transform the high priority requirements into appropriate technical characteristics. According to the priorities of product characteristics, the prior engineering parameters will be identified to be the key performances to redesign. For identifying the requirements and achieving the attractive design, we introduce the Kano model to construct the evaluation model. The proposed Kano-based evaluation procedure is mainly used in two stages of the innovative design. First, the evaluation process was used in QFD stage to help identify attractive customers' requirements, and the other was used in the extension stage to help assess concepts. The flowchart of proposed innovative design procedure with psychology-based evaluation has also been developed. A case study, exercise equipment design, is adopted to explain and verify feasibility of the proposed approach.
\end{abstract}

\section{Introduction}

Customer satisfaction, the major concern to many leading companies, has gradually become the most important factor during the design process. For identifying the design improvement ratio, satisfaction ratings have been widely used as the indicator of the performance of services or products in many companies. Hanan and Karp [1] state the following: "Customer satisfaction is the ultimate objective of every business: not to supply, not to sell, not to service, but to satisfy the needs that drive customers to do business." For the leading companies throughout the world, customer satisfaction strategies have become more and more important with increasing competition. They noticed that a higher degree of customer loyalty is often resulted from higher customer satisfaction. The purpose of marketing and design strategic is to create a high level of customer satisfaction and loyalty so as to win the sustainable development and competitive advantages. Therefore, in product design, identifying the key design attribute to gain customer satisfaction is very important.

Matzler et al. [2] indicate that customer satisfaction versus product quality has mostly been deemed as onedimensional relationship. As customers perceive the higher quality, the higher level their satisfaction increasing and vice versa. However, they noticed that even though highly fulfilling individual customer expectations does not represent a high level of customer satisfaction, the definitions of two types of customers' expectations, product quality perception and customer satisfaction, are different. Kano developed the model of customer satisfaction which identified the characteristics what impact the attributes of products and services on customer satisfaction.

The two-dimensional model developed by Kano et al. is used to classify the attributes of a product or service based on to what extend they can satisfy customer requirements [3]. Based on relationships between customer satisfaction and performance of a product or service, Berger et al. [4] 
defined three types of product requirements which influence customer satisfaction in different ways. These three different types of qualities are as follows: (1) the must-be or basic quality; (2) one-dimensional or performance quality; (3) the attractive or excitement quality. By using the Kano model, the relationship between performance criteria and customer satisfaction can be well understood so that the key performance of product design will also be identified.

For design decision making, listening to the voice of the customer (VOC) can gain the relevant information about matters which should be improved to increase customer satisfaction [5]. Zhang and Von Dran [6] developed a Web site quality model by applying the Kano quality model to a single type of Web site. The expectation and preference ranking of Web sites' quality factors are discussed. The Kano's model of quality was used in an exploratory investigation of customer quality expectations for a specific type of site (CNN.com). They find that users of a Web site distinguish three types of quality factors corresponding to their quality expectations; the quality nature of the factors may change over time and the same factor may have different quality identifications in different domains. Lai et al. [7] proposed a robust design method to improve quality perception by reducing the gap between the actual customer feeling and what they desired. Moreover, ambiguity has also been reduced by highly individualized characteristics of customers. The robust design approach focuses on bringing the mean closer to the desired target and simultaneously reducing quality variation. Sireli et al. [8] provide a step-by-step methodology, fine-tuned QFD, by combining Kano's model and QFD robustly, from the perspective of simultaneous multiple product design. Delice and Güngör [9] indicated that the values of DRs are often discrete instead of continuous in real world applications. They combined MILP model and Kano model to acquire the optimized solution from a limited number of alternative DRs (discrete values). Garibay et al. [5] proposed a tool which utilized a combination of the Quality Function Deployment (QFD) and Kano model to evaluate service quality. By applying the extension method, Wu et al. [10] developed the innovative procedure based on extensive QFD.

For the purposes of achieving higher customer satisfaction and the effectively optimal design decision-making, this study investigates how to integrate the Kano model and extensive QFD design approach. In this research, a mainly contribution is that a psychology-based evaluation procedure has been developed based on the Kano model. We proposed explicit and feasible intelligent innovation processes and evaluation method progressively. The feasibility will also be verified through design cases.

\section{Extensive QFD Innovative Design Procedure}

For systematically analyzing concrete or intangible products, Cai [11] proposed and developed a powerful tool, matterelement, and extension method. The extension method was derived from the extension theory that involves the matterelement theory and extension mathematics. Incompatible problem in the real world is the major research subject of extension theory. The applications of extension method have already extended to many field such as engineering, business, economics, sociology, management, and strategy $[12,13]$. The results of concept design research based on extension theory are described as follows:

(1) The extensible expression method of concept design knowledge.

(2) Construction of the rhombus thinking model of the conceptual design.

(3) Evaluation and redesign of concept design.

In this paper, the extensive QFD developed by Wu et al. [10] has been adopted for the innovative design procedure. In addition, the Kano-based evaluation method is developed to assist decision-making.

2.1. Extensive QFD. QFD is a structured design tool and is defined as follows: "A consumers' needs oriented tool which establishes the relationship between customer attributes and design parameters to be quantified through the HoQ (House of Quality), QFD helps recognize the customers' cognitions and discover the key design factors of products. Therefore, the direction of product development and market positioning can be determined." The goal of product planning phase is to translate customer requirements (CRs) into engineering characteristics (ECs) and determine the importance priorities. CRs should be acquired from market surveys or customer questionnaires. The acquired information can be used to calculate the relative and final importance of CRs and also identify the ECs. The final importance of ECs will be calculated and the relationship matrix also will be established, simultaneously.

Customer requirements-orientation is the main spirit of QFD. The most important creativity thinking process is to convert the functional qualities to the engineering design parameters for the customer requirements-oriented innovation design. The major procedure of QFD is to identify the customers' requirements and their priorities for the product based on the market surveys or customer questionnaires. Then, the designer should convert the requirements into appropriate technical measures to meet the needs. The priorities of product characteristics can be determined by translating important technical measures. The prior engineering parameters and the key requirements for redesign will be identified according to their characteristics. The extensive creativity activities can be expanded as follows:

(1) Extension method can assist the designer to translate customers' needs into product design attributes (technical measures).

(2) By extending the customers' voices, the corresponding product defects or the parameters needed to be improved will be identified.

During the two processes, extensibility of matter-element and extension method provide effective assistance to the designer in the translation processes of product design attributes and the establishments of engineering properties. The application of extension method can provide conceiving new products comprehensively and deeply. 
Matter-element, event-element, and their definitions with multicharacteristics are as follows:

Matter-element and event-element

$$
\begin{aligned}
& R(t)=(N(t), c, v(t)) ; \\
& I(t)=(d(t), b, u(t)) .
\end{aligned}
$$

Matter-element with multicharacteristics

$$
\begin{aligned}
& R(t)=(N(t), C, V(t)) ; \\
& I(t)=(d(t), B, U(T)) .
\end{aligned}
$$

Extending tree, the front end rhombus thinking, is a method for matter to outward expansion to offer organizational, structural, and multiorientated thinking.

The corresponding matter-elements and event-elements can be used to describe these relationships and interactions. Relationship-element, a $n$-dimensional matrix, is formed by relationship name $s(t)$, characteristics $a_{1}, a_{2}, \ldots, a_{n}$, and corresponding measured values

$$
\begin{aligned}
& w_{1}(t), w_{2}(t), \ldots, w_{n}(t) \\
& Q(t)=(s(t), A, W(t))
\end{aligned}
$$

Divergence, expansibility, relevance, and implication are the extensible properties of matter-element, event-element, and relationship-element. By interactive application of the extensive properties, the solution will not be limited by standard solutions $[12,14,15]$. Followings are two major procedures of proposed extensive QFD: "Procedure for Improve Product Design Attributes" and "Engineering Design Parameters Transfer Procedure."

(1) For "Improve Product Design Attributes," throughout the procedure of QFD, the extensibility of matter-element and extension method can be introduced into the course of improving product design attributes (technical measures) based on product defects found from customers' voice. The key step is "Transformation on the sub-matter-elements $R_{i}(i=1,2, \ldots, m)$ corresponding to functional defects and rearrange."

The transformation methods, such as replacement, addition/deletion, and expansion/contraction can be treated to the iso-matter-element but the addition/deletion and expansion/contraction should be treated to the distinct matterelement, that is, either separately or integrated transform submatter-elements for each shortcoming $R_{i}(i=1,2, \ldots, m)$

$$
T_{i} R_{i}=R_{i}^{*} \quad(i=1,2, \ldots, m) .
$$

The revised sub-matter-elements can be obtained by transforming the matter-element with shortcomings to a better one. Corresponding to the elements of $R$, a sequence of new products will occur.

(2) For the "Engineering Design Parameters Transfer Procedure," the main function is to translate product functional requirements into engineering design parameters. The key step is "Interactive using conjugate properties and transformation methods of the elements' certain characteristics to solve the design problems."

Analysis and understanding the matter from the material, systemic, dynamic, and oppositional properties, the structure of matter can be described comprehensively and the nature of development and change of matters can be revealed deeper. Real/imaginary, soft/hard, potential/significant, and positive/negative, the corresponding four pairs of opposing concepts, can be used to describe the composition of matters and assist the transformation and extension of matter-elements. For example, if we try to use the potential/significant properties to assist the redesign, we have to discover the latent required functions through customers' interview and then perform the transformation of matters to modify the ideas comprehensively. Thus, the new product $N$ possesses the required potential function that will be designed. Besides, the negative direction (negative values of function) part of product $N$, negative part of $N$ " $n g(c) N$ ", should be considered. The concepts will be modified by transformation operation to reduce adverse effects.

Finally, designers will get a variety of new product ideas by using basic transformations of matter-element as the following operations:

$$
T R=\prod_{i=1}^{n}\left(T_{i} R_{i}\right)=\prod_{i=1}^{n} \prod_{j=1}^{m}\left(T_{i j} R_{i j}\right) .
$$

2.2. Kano-Based Evaluation Procedure. Many concept design solutions can be obtained by processing the extensive innovation procedure. Rhombus thinking has two procedures, first stage is divergent thinking process which performs creative thinking and second stage is convergence stage, which is design evaluation stage. These possible solutions obtained in the divergent thinking stage should be evaluated to determine the optimal solutions. The convergent part of Rhombus thinking model is the procedure of evaluation for decision making.

In this paper, an evaluation method has been developed based on Kano model. The Kano model, developed by Noriaki Kano, is a theory of product development and customer satisfaction. As shown in Figure 1, Kano model classifies customer preferences into five categories, that is, attractive, one-dimensional, must-be, indifferent, and reverse quality. Attractive quality defined as the attributes of product, not normally expected, provides satisfaction while being achieved fully but does not cause dissatisfaction while not fulfilled. These attributes, which are classified as onedimensional quality, result in satisfaction while fulfilled and dissatisfaction while not fulfilled. The attributes, which are taken for granted while fulfilled but result in dissatisfaction while not fulfilled, are categorized as must-be quality. Indifferent quality means that these attributes refer to aspects that are neither good nor bad, and they do not result in either customer satisfaction or customer dissatisfaction. These attributes for reverse quality refer to a high degree of achievement resulting in dissatisfaction for some customer groups. Quality engineering which focuses on the physical 


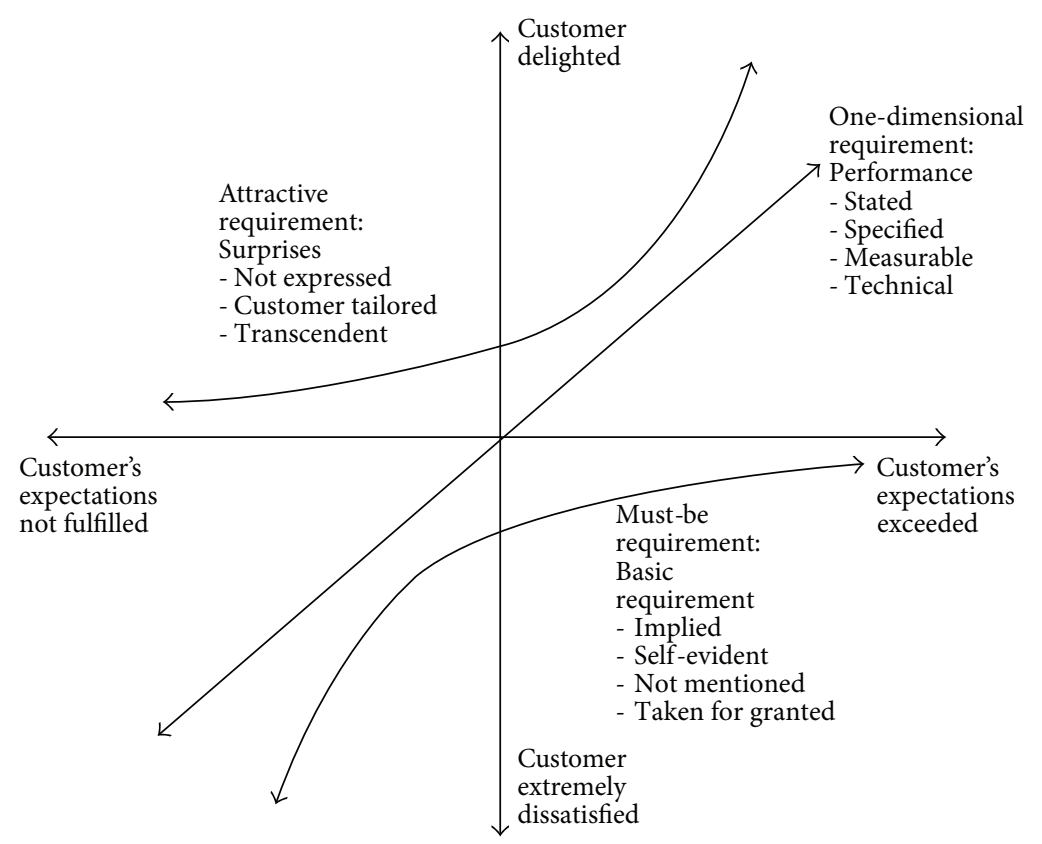

FIGURE 1: Kano's model of customer satisfaction [4].

level has prevailed so far. However, the aspect of quality proposed by Kano focuses on psychology.

In this research, the proposed Kano-based evaluation procedure was mainly used in two stages of the innovative design. First, the evaluation process was used in QFD stage to help identify attractive customers' needs, and the other was used in the extension stage to help assess concepts.

The application of QFD stage is to define and identify customers' requirements and then assign priorities to them. The Kano model can assist the QFD stage to provide an effective method to resolve the nature of customers' requirements and then assign the priorities [16]. Tan and Pawitra [17] suggested that the designer should pay more attention to attractive attributes first and then the one-dimensional and finally the must-be attributes. Garibay et al. [5] indicated that the integration of QFD and the Kano model is a suitable methodology for better listening and resolving customer requirements. The key step while applying QFD is to define customers' requirements and then to assign their priorities. It is necessary to discover the real and sufficient information about matters which satisfies customers so as to establish the priorities in a proper way based on the sufficient analysis. How to reprioritize customer requirements in QFD by using Kano model is the important issue in this approach. For the psychology-based evaluation procedure developed in this research, the Kano model is applicable not only to identify the customers' priorities but also to identify the attractive innovative conceptual design. It is very exciting for designers while the attractive factors are identified.

Noriaki Kano was the first person to develop a method to identify user requirement and expectation through a preference classification technique [3]. Kano Model can be used to determine users' requirements and exceed their expectations. Three categories of requirements influence user satisfaction in different ways (see [2]):

(i) Must-be user expects the basic qualities and will be dissatisfied if they are not fulfilled.

(ii) One-dimensional user will be satisfied if the qualities are fulfilled and dissatisfied if they are not fulfilled.

(iii) Attractive qualities exceed users' expectations, user might be excited if they are fulfilled but if they are not met, user will not be dissatisfied.

In the extensive innovation stage, that is, the concepts expansion stage, an evaluation characteristic will be defined in (2) and (3); that is, $c_{e}, b_{e}, a_{e}$ refers to $R(t), I(t)$, and $Q(t)$, separately. The corresponding values of evaluation characteristics will be obtained based on the Kano model. Attractive, one-dimensional, and must-be requirements as well as product requirements towards which the customer is indifferent or reverse can be classified by means of a questionnaire. For each product feature a pair of questions is formulated to which the customer can answer in one of five different ways [18]. The first question concerns the reaction of the customer if the product has that feature (functional form of the question) and the second concerns his reaction if the product does not have that feature (dysfunctional form of the question) (Tables 1 and 2) [16]. The questionnaire is evaluated as follows:

(1) After having combined the answers to the functional and dysfunctional question in the evaluation table, the results of the individual product criteria are listed in the table of results which shows the overall distribution of the requirement categories. 
TABLE 1: A pair of questions for psychological level evaluation [4].

\begin{tabular}{ll}
\hline & $\square$ I like it that way \\
Functional form of the & $\square$ It must be that way \\
question & $\square$ I am Neutral \\
& $\square$ I can live with it that way \\
& $\square$ I dislike that way \\
\hline & $\square$ I like it that way \\
& $\square$ It must be that way \\
Dysfunctional form of the & $\square$ I am Neutral \\
question & $\square$ I can live with it that way \\
& $\square$ I dislike that way
\end{tabular}

TABLE 2: Kano evaluation table [4].

\begin{tabular}{|c|c|c|c|c|c|}
\hline \multirow{2}{*}{$\begin{array}{l}\text { Customer } \\
\text { requirements }\end{array}$} & \multicolumn{5}{|c|}{ Dysfunctional (negative) question } \\
\hline & Like & Must-be & Neutral & Live with & Dislike \\
\hline \multicolumn{6}{|c|}{$\begin{array}{l}\text { Functional (positive) } \\
\text { question }\end{array}$} \\
\hline Like & Q & $A$ & $A$ & $A$ & $O$ \\
\hline Must-be & $R$ & $I$ & $I$ & $I$ & $M$ \\
\hline Neutral & $R$ & $I$ & $I$ & $I$ & $M$ \\
\hline Live with & $R$ & $I$ & $I$ & $I$ & $M$ \\
\hline Dislike & $R$ & $R$ & $R$ & $R$ & Q \\
\hline
\end{tabular}

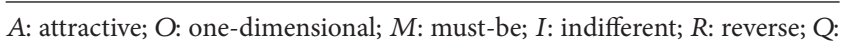
questionable.

(2) According to the frequency of responses to the questionnaires, the expectation levels of customers' requirements can be evaluated and interpreted.

Berger et al. [4] wanted to calculate an average of some sort while also preserving some idea of the spread over attractive, one-dimensional, and must-be features. They proposed the idea, customer satisfaction coefficient, to identify the degree of customers' satisfaction under the influence of "quality sufficient/insufficient" by reducing the data to two numbers: a positive number that is the relative value of meeting this customer requirement (versus the competition) and a negative number that is the relative cost of not meeting this customer requirement. These two numbers were labeled as "If we're better..." and "If we're worse...", abbreviated Better and Worse. To calculate the Better value, we added the attractive and one-dimensional columns and divided by the total number of attractive, one-dimensional, must-be, and indifferent responses. (Reverse and questionable responses were ignored.) For Worse, we added the must-be and onedimensional columns, divided by the same normalizing factor, and put a minus sign in front of the result to get the number.

The positive Better numbers are indicative that customer satisfaction will be increased by providing these (attractive and one-dimensional) elements and the negative Worse numbers are indicative that customer satisfaction will be decreased if these (one-dimensional and must-be) elements are not included. From a slightly different point of view,
Better indicates how much customer satisfaction is increased by us providing a feature (i.e., "If we're better" [than the competition], increase our score by this positive number); and Worse indicates how much customer satisfaction is decreased by us not providing the feature (i.e., "If we're worse" [than the competition], decrease our score by this number).

These formulas can be described as follows:

Customers satisfaction, CS (better)

$$
=\frac{(A+O)}{(A+O+M+I)},
$$

$$
\text { Customers dissatisfaction, CD (worse) }
$$

$$
=-\frac{(O+M)}{(A+O+M+I)} \text {. }
$$

Wang and Ji [19] indicated that the average impacts of each quality to customers' satisfaction can be reflected by formulas (6). Therefore, designers can identify the qualities whether they will fulfill user satisfaction or prevent the user from dissatisfaction. According to the extended options proposed by Chaudha et al. [20], the Kano category $(k)$ can be determined and the value is defined as $0,0.5,1$, and 1.5 for indifferent $(I)$, must-be $(M)$, one-dimensional $(O)$, and attractive $(A)$ respectively. Tontini [21] proposed the adjustment factor which is determined by Kano model and can be used directly in the QFD matrix. Consider

$$
\text { Adjustment factor }=\operatorname{Max}([C S],[C D]) \text {. }
$$

Garibay et al. [5] proposed the adjustment important $j$ which was obtained by multiplying the adjusted improvement ratio to user importance, $u$, the mean value calculated for each quality from the importance survey. Chaudha et al. [20] recommended the adjusted improvement ratio, $R_{1}$ :

$$
R_{1}=(1+f)^{k} \cdot \frac{t}{u}
$$

where $f=$ adjustment factor, $k=$ Kano category, and $t=$ user satisfaction target.

For clear understanding the priority of quality, we proposed the value, priority index, $P_{i}$. $P_{i}$ is defined as

$$
P_{i}=k \cdot \ln (1+f) \text {. }
$$

The proposed Kano-based evaluation procedure was mainly used in two stages of the innovative design. First, the evaluation process was used in QFD stage to help identify attractive customers' needs, and the other was used in the extension stage to help assess concepts. As shown in Figure 2, the flowchart of proposed innovative design procedure with psychology-based evaluation has also been developed.

\section{Illustrative Design Case}

The proposed invention procedure is used to expand a design case "Stationary Bike," the most favorite exercise equipment. The proposed approach, extensive QFD, has been adopted 


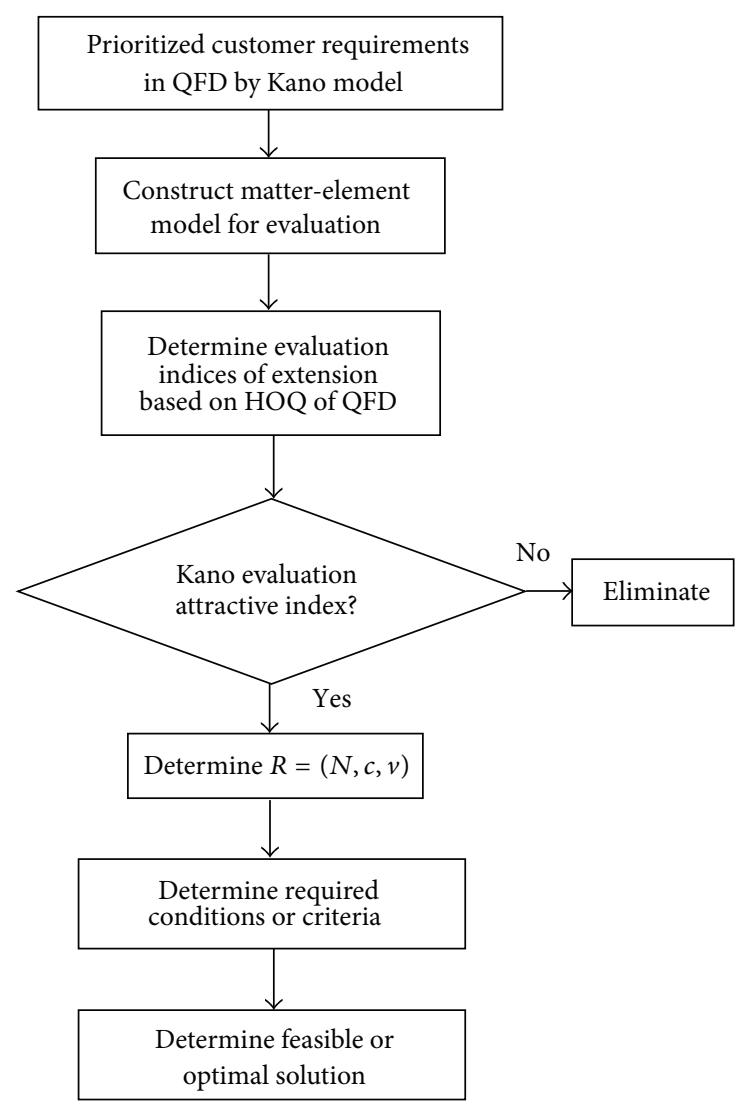

FIGURE 2: Flowchart of comprehensive evaluation.

to investigate the users' requirements and relative functional or ergonomic requirements. In the creative process, the extension method will be used to improve product design attributes and to determine the associated engineering design parameters. By applying the Kano evaluation model, the creative solution programs based on customers' satisfaction will thus be achieved.

3.1. Identify and Prioritize Customers' Requirements. First part of this stage is to identify the requirements of "Stationary Bike" by interviewing the users and translate the requirements to product design attributes. For the second part, proceeding the questionnaire checks for the users to gain the important requirements.

In this study, the cycling exercise amateurs are selected as the survey candidates. In order to avoid some important problems that are ignored, the gym trainers are also comprised. Gathering respondents' views, users' requirements are sorted out as Table 3. By interview with the experts, gym trainers and designers, we can translate the customers' requirements into design attributes more detailed and widely as shown in Table 4.

3.2. Kano-Based Evaluation. A total of 52 valid questionnaire data had been received. Taking the "Exercise Function" for example, the Kano-based evaluation results are shown in Tables 5 and 6.
TABLE 3: Requirements of stationary bike amateurs and trainers.

\begin{tabular}{lc}
\hline Overall riding comfortable & Safety \\
\hline Easy folded and stored & Attractive appearance \\
Easy to operate & Additional functions \\
Flexibility to adjust & Sturdy and durable \\
Entertaining & Interactivity \\
\hline
\end{tabular}

TABLE 4: Product design attributes.

\begin{tabular}{lll}
\hline Level 1 & \multicolumn{1}{c}{ Level 2 } & Level 3 \\
\hline \multirow{3}{*}{ Specifications } & Design for assembly \\
& & Weight \\
function & Safety & Maintenance \\
& & Emergency break performance \\
& & Structural strength \\
& Exercise & Diversified sport mode \\
& function & Interactivity with cellphone \\
& & Interactive multiplayer \\
& & Entertaining \\
\hline & Comfort & Heat dissipation \\
& & Suspension performance \\
& Comfortable operation \\
& & Attractive appearance \\
& & Adjustable speed or loading \\
& & Easy to operation \\
& & Easy to fold \\
& & Learnability of HCI \\
& & Elexible adjustment \\
& &
\end{tabular}

TABLE 5: Evaluation table of result.

\begin{tabular}{lcccccc}
\hline $\begin{array}{l}\text { Product } \\
\text { requirement }\end{array}$ & $A$ & $O$ & $M$ & $I$ & $R$ & Category \\
\hline $\begin{array}{l}\text { Diversified sport } \\
\text { mode }\end{array}$ & $30.8 \%$ & $34.6 \%$ & $19.2 \%$ & $15.4 \%$ & $0 \%$ & $O$ \\
$\begin{array}{l}\text { Interactivity with } \\
\text { cellphone }\end{array}$ & $48.1 \%$ & $28.8 \%$ & $9.6 \%$ & $11.5 \%$ & $1.9 \%$ & $A$ \\
$\begin{array}{l}\text { Interactive } \\
\text { multiplayer }\end{array}$ & $50 \%$ & $9.6 \%$ & $23.1 \%$ & $9.6 \%$ & $7.7 \%$ & $A$ \\
\begin{tabular}{l} 
Entertaining \\
\hline
\end{tabular} & $28.8 \%$ & $38.5 \%$ & $15.4 \%$ & $17.3 \%$ & $0 \%$ & $O$ \\
\hline
\end{tabular}

TABLE 6: Evaluation table of result.

\begin{tabular}{lcccccc}
\hline Product & $A$ & $O$ & $M$ & $I$ & $R$ & Category \\
\hline New design & $75 \%$ & $15.4 \%$ & $5.8 \%$ & $3.8 \%$ & $0 \%$ & $A$ \\
\hline
\end{tabular}

The evaluation results indicate that the design attributes "Interactivity with Cellphone" and "Interactive Multiplayer" are attractive quality, but "Diversified Sport Mode" and "Entertaining" are classified as one-dimensional quality. The attractive qualities, "Interactivity with Cellphone" and "Interactive Multiplayer," are what we desired. 
3.3. Extensive Procedures of Innovation Design. Based on the Kano evaluation model, the attractive qualities of "Exercise Function" are "Interactivity with Cellphone" and "Interactive Multiplayer". The top priority of attractive qualities is "Interactive Multiplayer." The extension of matter-element can be expressed as

$$
\begin{aligned}
R_{1} & =\left(N, c_{1}, v_{n}\right) \\
& =(\text { Interactive Multiplayer, type, scene }) \\
& =(\text { Interactive Multiplayer, type, virtual reality }) \\
& \ldots \text { etc. }
\end{aligned}
$$

From the extension of matter-element, there are two types of Interactive Multiplayer, that is, "distanced virtual interactivity" and "face to face interaction." Then, we derive and confirm the "hypostatic characteristics" from "functional characteristics" and then the corresponding "certain characteristics" will also be derived and confirmed. Then, we use the corresponding four pairs of opposing concepts such as real/imaginary, soft/hard, potential/significant, and positive/negative to describe the composition of matters and assist the transformation and extension of matter-elements.

Thus, the event-element and relationship-element can be expressed as follows:

The extension of event-element,

$I$

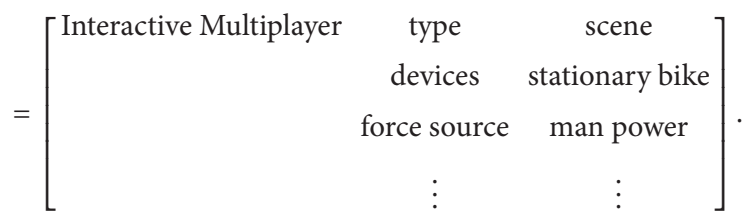

The extension of relationship-element

Q

$=\left[\begin{array}{ccc}\text { Interactivity } & \text { Major device } & \text { Stationary bike } \\ \text { Relative device } & \text { Horse Riding } \\ \text { Drive method } & \text { Manpower } \\ \text { Transmission } & \text { Gear Chain or Belt } \\ \text { Entertaining } & \text { Good } \\ \text { Advantages } & \text { Friendship } \\ \text { Evaluation } & A \\ \vdots & \vdots\end{array}\right]$

The new extension model can be devised by transformation process. Then, the new concept can also be derived. The new concept of exercise equipment is "A Stationary Bike integrated with Horse-riding Fitness Equipment." Two exercisers can use the device simultaneously. One exerciser rides the "Stationary Bike" and the pedaling force provides the driving force of "Horse-riding Fitness Equipment".
3.4. Kano-Based Evaluation. Then, we will use Kano evaluation method to assess and identify what kind of quality is this design. A total of 52 valid questionnaire data had been received. The evaluation results indicate that the solution is classified as "attractive" quality. An attractive quality is what we desired.

Repeating the innovative procedure, optimal new concepts design will occur.

\section{Conclusion}

Based on the QFD, extension method, and Kano model, this study proposes an approach to innovative design problems with the aid of questionnaires. Customers' needs and the priorities of product characteristics can be identified by QFD integrated with Kano model.

The proposed innovative design procedure combines the QFD procedure and extension method to improve the efficiency and extent of concept evolutions. Moreover, a psychological-level characteristic and evaluation procedure have also been developed. For achieving the attractive design, we introduce the Kano model to construct the evaluation model. The proposed Kano-based evaluation procedure was mainly used in two stages of the innovative design. First, the evaluation process was used in QFD stage to help identify attractive customers' needs, and the other was used in the extension stage to help assess concepts.

In this study, we use the extensive QFD and extensibility of matter-element to clarify and expand the customers' requirements and design concept. The extension method can help people resolve problems separately by decomposing them, recombining the problems, and then searching for the feasible solutions, assisting the designer to extend and deduce concepts widely. Through the transformation rules of extension theory, various innovative design plans developed widely and deeply. The result includes the following:

(1) The major contribution is that a psychology-based evaluation procedure has been developed based on the Kano model.

(2) An explicit and feasible intelligent innovation procedure to transfer customers' requirements to design prototype under psychological-level evaluation was developed.

(3) Customers' requirements of "Stationary Bike" have been discussed by interviewing the users and then translated to product design attributes. Moreover, the Kano-based questionnaires check for the users to find the important requirements.

(4) The new design concept of exercise equipment: “A new exercise equipment which integrated with Stationary Bike and Horse-riding Fitness Equipment" has been successfully designed.

\section{Conflict of Interests}

The authors declare that there is no conflict of interests regarding the publication of this paper. 


\section{References}

[1] M. Hanan and P. Karp, Customer Satisfaction: How to Maximize, Measure and Market Your Company's "Ultimate Product", American Marketing Association, New York, NY, USA, 1998.

[2] K. Matzler, H. H. Hinterhuber, F. Bailom, and E. Sauerwein, "How to delight your customers," Journal of Product \& Brand Management, vol. 5, no. 2, pp. 6-18, 1996.

[3] N. Kano, K. Seraku, F. Takahashi, and S. Tsuji, "Attractive quality and must-be quality Hinshitsu quality," The Journal of the Japanese Society for Quality Control, vol. 14, no. 2, pp. 39-48, 1984.

[4] C. Berger, R. Blauth, D. Boger et al., "Kano's methods for understanding customer-defined quality," Center For Quality Management Journal, vol. 2, no. 4, pp. 3-35, 1993.

[5] C. Garibay, H. Gutiérrez, and A. Figueroa, "Evaluation of a digital library by means of quality function deployment (QFD) and the Kano model," The Journal of Academic Librarianship, vol. 36, no. 2, pp. 125-132, 2010.

[6] P. Zhang and G. M. Von Dran, "User expectations and rankings of quality factors in different web site domains," International Journal of Electronic Commerce, vol. 6, no. 2, pp. 9-33, 2002.

[7] H. H. Lai, Y. M. Chang, and H. C. Chang, "A robust design approach for enhancing the feeling quality of a product: a car profile case study," International Journal of Industrial Ergonomics, vol. 35, no. 5, pp. 445-460, 2005.

[8] Y. Sireli, P. Kauffmann, and E. Ozan, "Integration of Kano's model into QFD for multiple product design," IEEE Transactions on Engineering Management, vol. 54, no. 2, pp. 380-390, 2007.

[9] E. K. Delice and Z. Güngör, "A new mixed integer linear programming model for product development using quality function deployment," Computers and Industrial Engineering, vol. 57, no. 3, pp. 906-912, 2009.

[10] C.-T. Wu, T.-S. Pan, M.-H. Shao, and C.-S. Wu, "An extensive QFD and evaluation procedure for innovative design," Mathematical Problems in Engineering, vol. 2013, Article ID 935984, 7 pages, 2013.

[11] W. Cai, "Essentials of matter-element analysis," Journal of Artificial Intelligences, vol. 2, 1983.

[12] W. L. Wang and Y. W. Zhao, "Explore the extensive decisionmaking of mechanical intelligent CAD," System Engineering Theory and Practice, vol. 18, no. 2, p. 114, 1998.

[13] Y. W. Zhao, "Extensive synthesis assess of the conceptual product design of mechanical engineering," Software Journal (Supplementary Issue), vol. 9, pp. 60-62, 1998.

[14] W. Cai, Matter-Element Model and Its Application, Science and Technology Literature Press, Beijing, China, 1994.

[15] W. Cai, C. Y. Yang, and W. C. Lin, Extensive Engineering Method, Science Press, Beijing, China, 1997.

[16] K. Matzler and H. H. Hinterhuber, "How to make product development projects more successful by integrating Kano's model of customer satisfaction into quality function deployment," Technovation, vol. 18, no. 1, pp. 25-38, 1998.

[17] K. C. Tan and T. A. Pawitra, "Integrating SERVQUAL and Kano's model into QFD for service excellence development," Managing Service Quality, vol. 11, no. 6, pp. 418-430, 2001.

[18] L. P. Sullivan, "The seven stages in company-wide quality control," Quality Progress, vol. 19, no. 5, pp. 77-83, 1986.

[19] T. Wang and P. Ji, "Understanding customer needs through quantitative analysis of Kano's model," International Journal of Quality \& Reliability Management, vol. 27, no. 2, pp. 173-184, 2010.
[20] A. Chaudha, R. Jain, A. R. Singh, and P. K. Mishra, "Integration of kano's model into quality function deployment (QFD)," International Journal of Advanced Manufacturing Technology, vol. 53, no. 5-8, pp. 689-698, 2011.

[21] G. Tontini, "Integrating the kano model and QFD for designing new products," Total Quality Management \& Business Excellence, vol. 18, no. 6, pp. 599-612, 2007. 


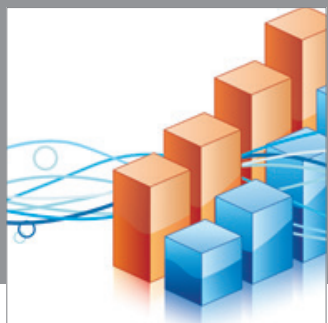

Advances in

Operations Research

mansans

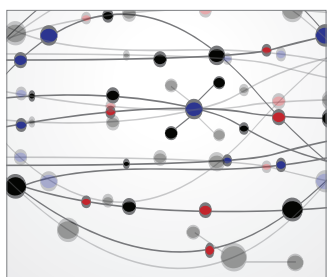

The Scientific World Journal
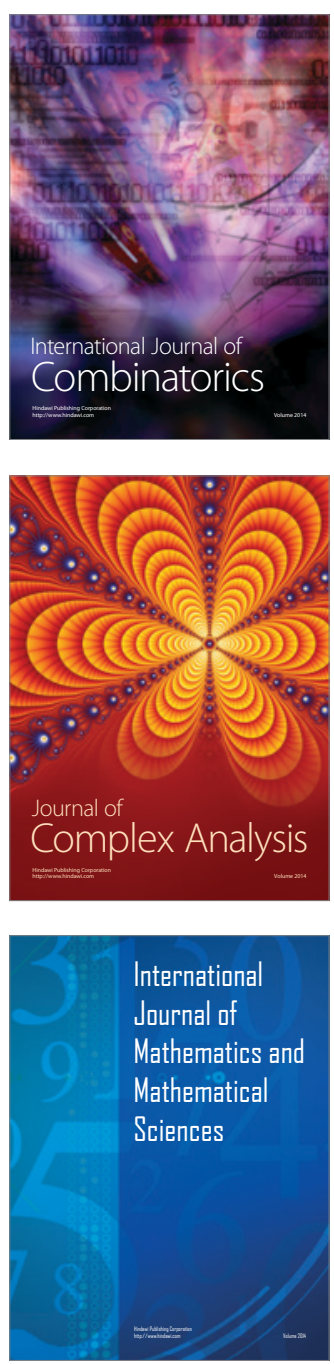
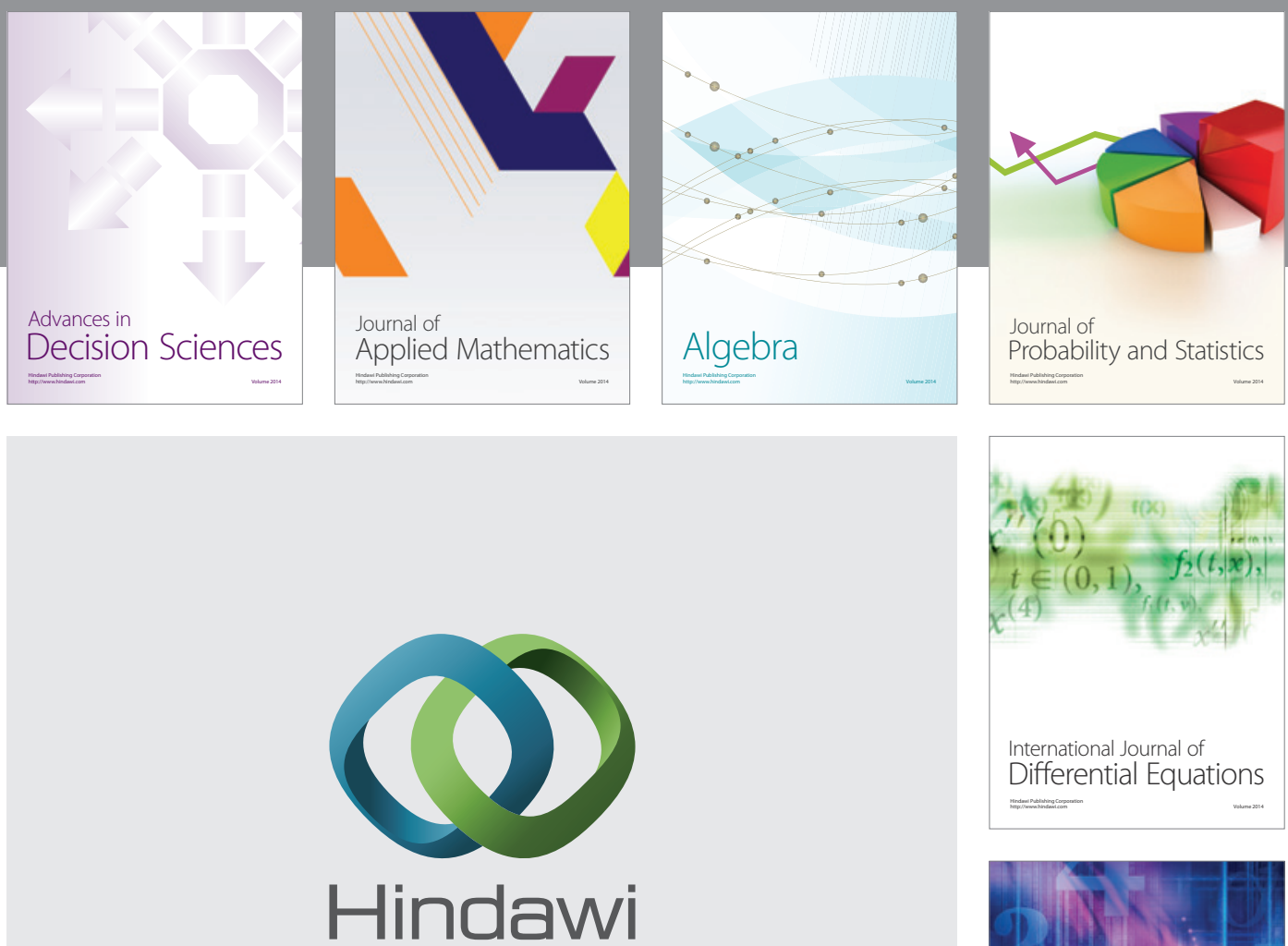

Submit your manuscripts at http://www.hindawi.com
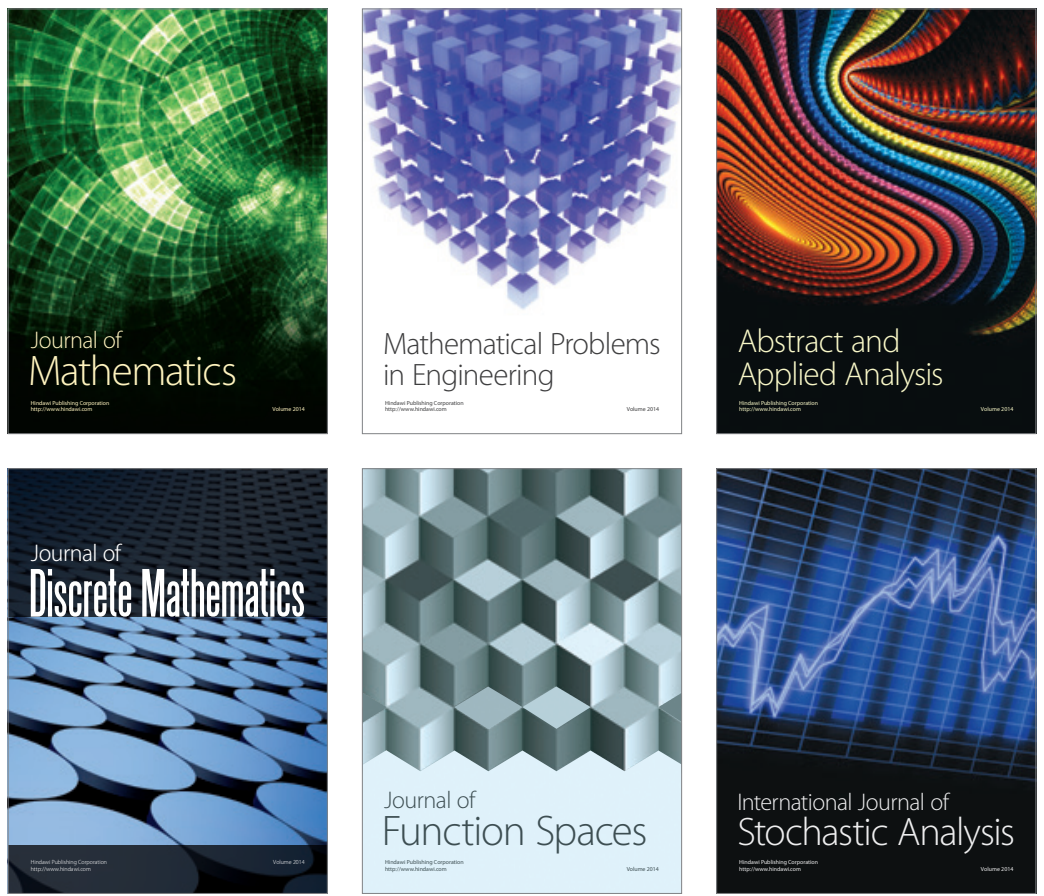

Journal of

Function Spaces

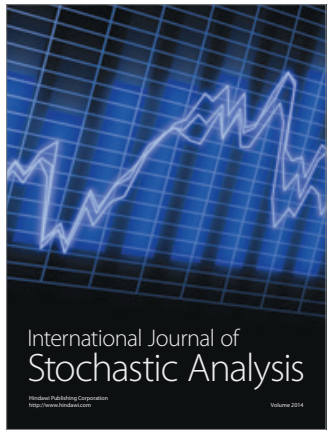

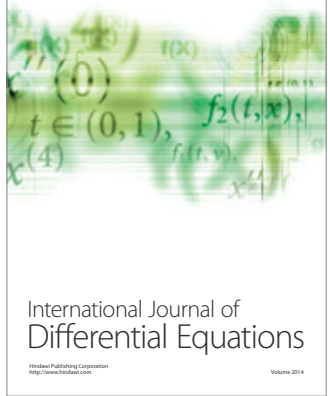
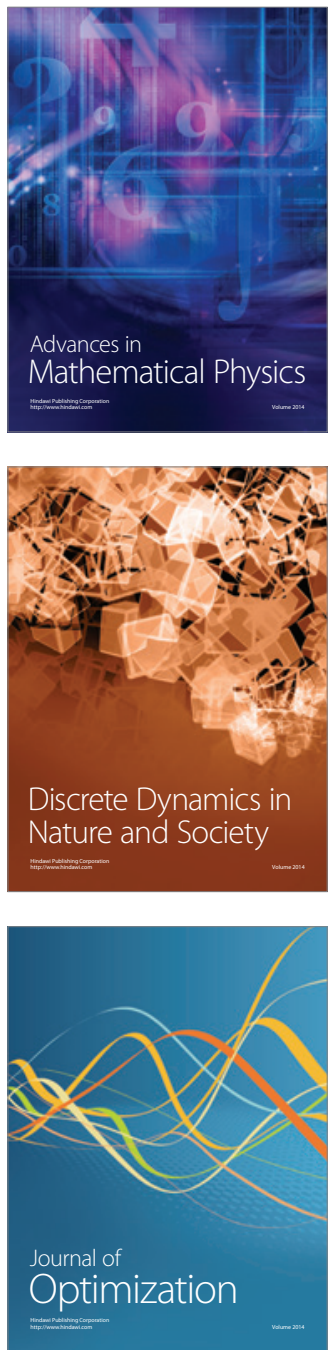